United Kingdom the imports were valued at 405,000 ticals. Japanese competition was confined mainly to cheap electrical goods, including lamps, and was responsible for a total of 330,000 ticals.

Comparing these figures with those for 1936-37, during which period Thailand imported nearly $2 \frac{1}{2}$ million ticals worth of electrical goods and apparatus, it is possible from the figures given to gauge to some extent the growth of the market. Figures for the total of all imports show that in 1936-37, the United Kingdom supplied goods to the value of more than 11 million ticals; Germany nearly 6 million ticals, and Japan more than 28 million ticals. For 1937-38 they show that the total of goods supplied were more than 13 million for the United Kingdom, nearly 7 million from Germany, and 22 million from Japan. This reflects a slackening of the Japanese competition.

Bangkok, the principal city, is developing rapidly. Up-to-date electric tramways are in operation. The first public wireless service between Thailand and foreign countries was inaugurated in 1929, and to-day Bangkok is in direct communication with eleven foreign stations-Berlin, London, Paris, Tokyo,
Hong Kong, Manila, Saigong, Bandoeng (Netherlands East Indies), Calcutta, Penang and Rangoon.

There is in operation a wireless telephone service between Thailand and Europe, as well as a radio picture telegraphic service and radio service for air and marine navigation. For internal wireless communications, stations have been established at various centres. In 1937 a medium wave transmitter of $10 \mathrm{kw}$., working on a wave-length of 400 metres, was added. Work has now been begun on the erection of a more powerful transmitter near Bangkok. It will be rated at $100 \mathrm{kw}$. Six studios and three announcers' booths are to be installed in a new General Post Office building included in the scheme.

The language problem should not prove a bar to trade, for English is widely used commercially, and it is only in bazaar work that a knowledge of the national tongue is necessary. While, by comparison with other overseas markets, Thailand is as yet only small when considered from the electrical exporter's point of view, it is a market which will undoubtedly expand in the next few years.

\title{
FREEZING AND COLD STORAGE OF FISH
}

\begin{abstract}
A REPORT from the California State Fisheries A Laboratory* claims that the problem of preserving tuna on fishing voyages of several weeks duration, in good condition for canning, has been solved-at least on a small scale-by the application of freezing and cold storage. This announcement may serve as a reminder that the problem of so improving the preservation of fish at sea as to reap the full benefit of the ever wider extension of fishing made possible by the construction of larger, more speedy and generally more efficient catching vessels, is also a pressing one in Europe, and that its solution by freezing and cold storage has been repeatedly advocated of recent years by the Food Investigation Board on the basis of work done at the Torry Research Station, Aberdeen.

While most modern British fishing vessels success-
\end{abstract} fully undertake voyages lasting three weeks or even longer, some reaching to well within the Arctic Circle, the universally employed means of preserving the fish, namely, storage in crushed ice, have in such circumstances proved inadequate, with the result that a considerable proportion of the total catch is landed in poor condition. Ice, in fact, will normally preserve white fish in really fresh condition for little more than one week. Freezing, on the other hand, promised not only to avoid staleness in long-distance fishing but also, if cold storage were continued on shore, to steady available supplies of the various food fishes independently of seasons and circumstances. Research has clearly shown that fish of all sorts can be kept in a condition practically as good as freshly caught for several months-even for much longer in the case of most white fish-if certain technical principles are observed. The fish must be frozen while strictly fresh and stored at temperatures in the range $-20^{\circ}$

* The Refrigeration of Tuna. Progress Report No. 2. (California State Fisheries Laboratory, Terminal Island, California.) to $-30^{\circ} \mathrm{C}$. In addition, freezing to these temperatures should preferably be completed within two or three hours. Only by employing such low temperatures is it possible sufficiently to retard various types of deteriorative change affecting odour, flavour and texturet.

The poor quality of the relatively small amount of fish frozen annually in the past must be held responsible for such prejudice against frozen fish as now exists. There appears to be little doubt that these fish were frequently frozen when already stale, and they were certainly stored at much too high temperatures, for example, $-6^{\circ}$ to $-10^{\circ} \mathrm{C}$., besides being as a rule very slowly frozen.

Unless a shore station can be established very near abundant fishing grounds, as, for example, in eastern Canada or Iceland, or in Great Britain with respect to the herring fishery, it is necessary to freeze the fish on board ship. A large factory ship with an attendant flotilla of small catching vessels could range remote seas for months at a time; alternatively, a super-trawler fitted to freeze and store as well as catch fish could operate nearer home for periods of some weeks. The former scheme has already been tested by British enterprise and the latter by French ; and with return to peace conditions it is to be hoped that these pioneer attempts will be followed up, and that eventually Great Britain may be assured at all times of a steady supply of all kinds of fish of uniformly high quality. It is of present interest to note that part of the shortage in the home supply occasioned by the War is being met by the import of frozen fish; but it is well also to remember that at such a time considerable difficulties may frequently stand in the way of treating the fish in the best possible manner.

Geo. A. Reay. 